\title{
Design of Room Temperature Electrically Pumped Visible Semiconductor
} Nanolasers

Fan, Yuanlong; Shore, K. Alan

\section{IEEE Journal of Quantum Electronics}

DOI:

10.1109/JQE.2018.2869332

Published: 01/10/2018

Peer reviewed version

Cyswllt i'r cyhoeddiad / Link to publication

Dyfyniad o'r fersiwn a gyhoeddwyd / Citation for published version (APA):

Fan, Y., \& Shore, K. A. (2018). Design of Room Temperature Electrically Pumped Visible Semiconductor Nanolasers. IEEE Journal of Quantum Electronics, 54(5), [2000907]. https://doi.org/10.1109/JQE.2018.2869332

\footnotetext{
Hawliau Cyffredinol / General rights

Copyright and moral rights for the publications made accessible in the public portal are retained by the authors and/or other copyright owners and it is a condition of accessing publications that users recognise and abide by the legal requirements associated with these rights.

- Users may download and print one copy of any publication from the public portal for the purpose of private study or research.

- You may not further distribute the material or use it for any profit-making activity or commercial gain

- You may freely distribute the URL identifying the publication in the public portal ?
}

Take down policy

If you believe that this document breaches copyright please contact us providing details, and we will remove access to the work immediately and investigate your claim. 


\title{
Design of Room Temperature Electrically Pumped Visible Semiconductor Nanolasers
}

\author{
Yuanlong Fan and K. Alan Shore, Senior Member, IEEE
}

\begin{abstract}
This paper presents a comprehensive theoretical study of the optical and thermal properties of an electrically pumped semiconductor nanolaser (SNL) having an GaN/(InGaN/GaN MQWs)/GaN core shell structure. Numerical results show that the lasing whispering-gallery mode (WGM) has a threshold gain of $413 \mathrm{~cm}^{-1}$. Furthermore, it is shown that when it is operated well-above threshold, the device temperature increases by only $22 \mathrm{~K}$ above an ambient temperature of $300 \mathrm{~K}$. These promising results are attributed to the strong mode confinement in the active region and the good thermal properties of the material system of the proposed structure. The results presented in this paper offer guidelines for fabrication of electrically pumped room temperature continuous wave SNL operating in the visible spectral region.
\end{abstract}

Index Terms-semiconductor nanolasers, photonic integrated circuits, gallium nitride.

\section{INTRODUCTION}

$\mathrm{D}$ URING the last two decades, extensive research effort has been devoted to the design of semiconductor nanolasers (SNLs) whose size are generally of order the lasing wavelength or even subwavelength scale [1-3]. Apart from their ultra-small size, SNLs are also characterized by their low power consumption [4-6], potential for high modulation bandwidth [7-9] and good compatibility with existing technologies such as photonic integrated circuits and lab-on-a-chip [10-12].

Amongst various existing SNLs [13-30], the so-called metal coated SNL (MCSNL) [15, 17, 23, 25, 26, 31, 32] has gained much attention in recent years due to its ingenious structure. The MCSNL mainly consists of an axially double heterostructured $\mathrm{p}-\mathrm{i}-\mathrm{n}$ pillar, a thin insulating layer surrounding the pillar and metal encapsulating the insulating layer and the pillar. Such configuration has the following advantages:

- Ease of fabrication: the pillar can be formed using standard dry-etching techniques, followed by thin-film deposition and sputtering to introduce the insulating layer and metal respectively [3];

- The choice of two alternative modes: depending on the thickness of the insulating layer, either photonic or plasmonic modes can be supported;

This work is supported by United Kingdom Engineering and Physical Sciences Research Council (U.K. EPSRC Grant No. EP/P006027/1). (Corresponding author: Yuanlong Fan.)

Yuanlong Fan and K. Alan Shore are with School of Electronic Engineering, Bangor University, Wales, LL57 1UT, United Kingdom (e-mail: y.fan@bangor.ac.uk; k.a.shore@bangor.ac.uk).
- The ease of electrical injection: the carriers can be injected through the top of the pillar via the coated metal and the base of the pillar via a large-area lateral contact. At the same time, the insulating layer prevents shorting of the diode junction;

- An ultra-small footprint (smaller than free-space laser wavelength $\lambda_{0}$ ) in all three dimensions due to the ability of the metal to tightly confine the mode to challenge the diffraction limit $\left(\lambda_{0} / 2 / n\right.$, where $n$ is the refractive index).

- The elimination of optical interference between adjacent devices in photonic integrated circuits due to the coated metal [32].

The first MCSNL under electrical injection was experimentally demonstrated by Hill et al. in 2007 [15]. Continuous wave $(\mathrm{CW})$ lasing at the wavelength of around 1.4 $\mu \mathrm{m}$ was observed with a cylindrical pillar of diameter $260 \mathrm{~nm}$ which almost reaches the diffraction limit. However, this device was operated at cryogenic temperature $(77 \mathrm{~K})$ due to the high optical loss in the metal at higher temperature. Since then, various attempts have been made to further decrease the size of the MCSNL and increase the operating temperature by compensating the loss introduced by the metal. For example, in 2011, an operating temperature of $140 \mathrm{~K}$ was achieved [23] using pillar undercut to improve the vertical mode confinement and subsequently lower the threshold gain. Theoretical work has also been undertaken to explore the possibility of room temperature (RT) operation for such undercut structures [32, 33]. Another method to reduce the metal loss is the use of a thick insulating layer between the active region and the metal to reduce the modal overlap with the metal [19, 34]. With these efforts, in 2012, RT CW electrical injection operation of MCSNL lasing at $1.55 \mu \mathrm{m}$ was achieved [25] based on a rectangular pillar with a volume of only $0.42 \lambda_{0}{ }^{3}$.

After successfully demonstrating electrically pumped RT CW MCSNL operating in the near infrared spectral region, it is natural to consider if such a structure may also be utilized in the visible spectral range where demand for novel sources arises from various emerging technologies such as $\mathrm{Li}-\mathrm{Fi}$ and ultra-high definition (UHD) displays. However, to date, there have been no reports of RT CW electrical pumped MCSNLs or indeed any other SNLs, e.g., surface plasmonic SNLs which currently can be operated under RT optical injection with extremely small cavity sizes [35-37], in the visible spectral range. One likely reason is the poor mode confinement caused by the small refractive index difference between relevant materials of the cladding and active region. For example, in a 
near infrared MCSNL with $\lambda_{0}=1.55 \mu \mathrm{m}$, the pillar of $\mathrm{InP} / \mathrm{InGaAs} / \mathrm{InP}$ has refractive indices of 3.1/3.4/3.1 [31] where the effective refractive index of InP can be further decreased by introducing undercut as mentioned above. However, in the visible MCSNL with $\lambda_{0}=465 \mathrm{~nm}$, if the pillar is $\mathrm{GaN} /(\mathrm{InGaN} / \mathrm{GaN} \mathrm{MQWs}) / \mathrm{GaN}$ which is commonly used in existing visible SNLs [27, 29, 30, 38], the refractive indices are 2.42/2.45/2.42 [39]. This gives a refractive index difference of 0.03 which is ten times smaller than that of the near infrared MCSNL. Moreover, it is challenging to undercut $\mathrm{GaN}$ due to its intrinsic crystal structure.

Recently, a radially double heterostructured p-i-n pillar structure SNL [29], namely the core-shell SNL, was experimentally demonstrated to tackle the above-mentioned issue in the visible spectral range. The core of this structure is the $\mathrm{n}$ doped $\mathrm{GaN}$ which is surrounded by $\mathrm{InGaN} / \mathrm{GaN}$ MQWs and then the outer shell which is $\mathrm{p}$ doped $\mathrm{GaN}$. In such a structure, the volume of the active region is one or more orders of magnitude greater than that of the axially double heterostructured p-i-n pillar. Moreover, the quantum-confined stark effect (QCSE) in the MQWs is eliminated which leads to a higher quantum efficiency and spectral stability [29, 40]. Lower transparency carrier density and Auger coefficient were also reported [41, 42] which should assist to decrease the lasing threshold. Lasing at a wavelength of $391 \mathrm{~nm}$ was observed at RT but under pulsed optical pumping. To achieve electrical pumping without significant increase of temperature, one possible way is to coat the core-shell SNL with metal which is similar to that which has been done for near infrared MCSNLs.

The aim of this paper is to numerically investigate the possibility of lasing behaviour in the visible of electrically pumped RT CW MCSNL with a core-shell structure. Firstly, the numerical model for the core-shell MCSNL is introduced where its three main physical properties are considered, namely optical, electrical and thermal properties. Such a structure will be shown to have low losses. By combining with the electrical and thermal simulations, the possibility of lasing behaviour of the core-shell MCSNL is discussed. Finally, conclusions are drawn based on the results obtained.

\section{NUMERICAL MODEL}

A schematic illustration of the core-shell MCSNL and its cross-sectional-view are, respectively, shown in Fig. 1 (a) and (b). The core-shell MCSNL is situated on a GaN-on-Sapphire substrate where $\mathrm{GaN}$ is $\mathrm{N}$ doped and used as a contact layer connected to the electrical contact ( $\mathrm{N}$ Contact). The core of the MCSNL is $\mathrm{N} \mathrm{GaN}$ which is sequentially and uniformly coated by the shells of $\mathrm{InGaN} / \mathrm{GaN}$ MQWs, $\mathrm{P} \mathrm{GaN}, \mathrm{SiO}_{2}$ and silver respectively with a thickness of $t_{M Q W}, t_{P}, t_{S}$ and $t_{M}$. The $\mathrm{SiO}_{2}$ prevents electrically shorting the diode. Silver is used to confine the mode and as a contact layer connecting to the $\mathrm{P}$ Contact. The fabrication process of the $\mathrm{GaN} /(\mathrm{InGaN} / \mathrm{GaN}$ MQWs)/GaN based core-shell structure can be found in [29, 30] and the method in [23] can be used to introduce the shells of $\mathrm{SiO}_{2}$ and silver. The size of each layer is shown in Table I. It should be pointed out that fabricated devices may deviate from the ideal in, for example, having some side-wall tilt. In

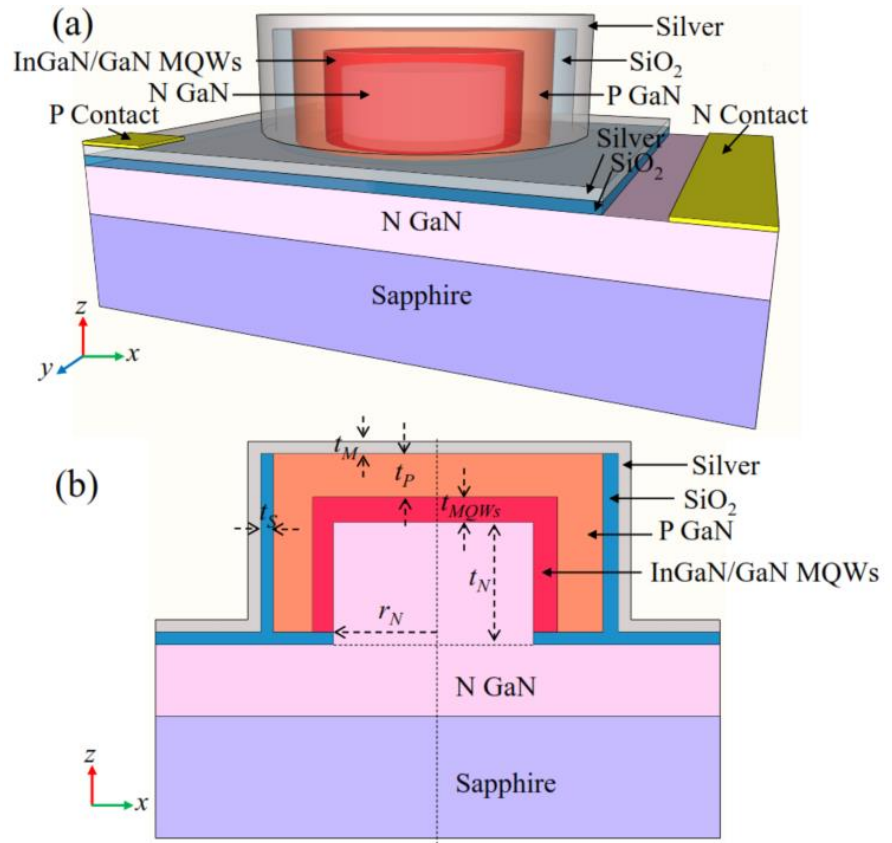

Fig. 1. The schematic illustration of the core-shell MCSNL. (a) 3D view, (b) cross-sectional-view.

addition, surface roughness may be introduced in the fabrication process. Such imperfections can degrade the performance of SNL [33, 43]. Therefore, the design of a robust SNL whose performance is substantially insensitive to such fabrication processes is desired. In the following section (Section III), it shows the proposed SNL has a low threshold gain which is more than four times lower than the available material gain calculated in [44], thus providing a significant immunity to defects introduced in the fabrication process.

TABLE I

THE SIZE OF EACH LAYER OF THE MCCSSNL

\begin{tabular}{ccc}
\hline \hline Layer Name & Material & Size \\
\hline N Doped Core & $\mathrm{N} \mathrm{GaN}$ & $r_{N}=200 \mathrm{~nm}, t_{N}=425-625 \mathrm{~nm}$ \\
InGaN in MQWs & $\mathrm{InGaN}$ & $2 \mathrm{~nm}$ \\
GaN in MQWs & $\mathrm{GaN}$ & $10 \mathrm{~nm}$ \\
MQWs & $\mathrm{InGaN} / \mathrm{GaN}$ & $t_{M Q W}=8 \mathrm{pairs}$ \\
P Doped Shell & $\mathrm{P} \mathrm{GaN}$ & $t_{P}=35-75 \mathrm{~nm}$ \\
Insulating Shell & $\mathrm{SiO}_{2}$ & $t_{S}=20-60 \mathrm{~nm}$ \\
Metal Shell & $\mathrm{Ag}$ & $t_{M}=40 \mathrm{~nm}$ \\
\hline \hline
\end{tabular}

A commercial simulator (COMSOL Multiphysics) based on the finite element method (FEM) [45] is used to perform the numerical simulations of the core-shell MCSNL. In particular, three main physical properties of the core-shell MCSNL are investigated, namely optical, electrical and thermal properties which are respectively simulated using Optics, Semiconductor and Heat Transfer modules provided by the COMSOL. Details of the model in each module is described in the following sub-sections.

\section{A. Model for Optical Simulations}

In the model, the core-shell MCSNL is surrounded by the air which is then enclosed by perfect matched layers (PMLs) to ensure no back-reflections of the light. The maximum element size for the finite element analysis and refractive index of each 
layer used in the simulations are listed in Table II. Note that the maximum element size should be limited to a fraction of the wavelength; the quicker the field is expected to change, the smaller the maximum element size which should be used.

TABLE II

MAXIMUM ELEMENT SIZE AND REFRACTIVE INDEX USED IN THE OPTICAL SIMULATIONS

\begin{tabular}{|c|c|c|}
\hline Material & $\begin{array}{c}\text { Maximum } \\
\text { Element Size }\end{array}$ & $\begin{array}{l}\text { Refractive Index } \\
\left(\lambda_{0}=465 \mathrm{~nm}\right)\end{array}$ \\
\hline $\mathrm{NGaN}$ & $\lambda_{0} / n_{-\mathrm{GaN}} / 3$ & $n_{-\mathrm{GaN}}=2.42[39]$ \\
\hline InGaN/GaN MQWs & $\lambda_{0} / n_{-} \mathrm{MQW} / 4$ & $n_{-}{ }_{\mathrm{MQW}}=2.45[39]$ \\
\hline $\mathrm{PGaN}$ & $\lambda_{0} / n_{-} \mathrm{GaN} / 3$ & $n \_\mathrm{GaN}=2.42[39]$ \\
\hline $\mathrm{SiO}_{2}$ & $\lambda d n_{-} \mathrm{SiO}_{2} / 4$ & $n \_\mathrm{SiO}_{2}=1.55[48]$ \\
\hline Sapphire & $\lambda d n_{-}$Sapphire $/ 4$ & $n \_$sapphire $=1.78$ [49] \\
\hline $\mathrm{Ag}$ & $\lambda d / 4$ & $n_{-} \mathrm{Ag}=0.05-2.80 \mathrm{i}[50]$ \\
\hline Air & $\lambda d / 4$ & $n_{-}$Air $=1[51]$ \\
\hline
\end{tabular}

Full 3D optical simulations are performed using the electromagnetic waves (frequency domain) interface in the Optics module which finds the eigenmodes for a given cavity by solving the wave equations. The PARDISO solver in the COMSOL is used to search for eigenmodes around a preset initial guess of the free-space resonance wavelength $\lambda_{0}=465 \mathrm{~nm}$ which corresponds to the peak of the gain spectrum calculated in [44]. The number of returned eigenmodes is set to be 100 which gives the modes with free-space wavelengths within a $25-35 \mathrm{~nm}$ range of $\lambda_{0}$, depending on the size of the laser. These eigenmodes includes both physical and spurious modes which can be distinguished by their spatial variations. The physical modes have spatial variations that are comparable to the cavity size whereas the spurious modes have spatial variations that are comparable to the mesh size [46]. After filtering out the spurious modes, the threshold gain is calculated and compared with the material gain calculated in [44] to examine the possibility of lasing in the proposed core-shell MCSNL. The threshold gain, $g_{\text {th }}$ is calculated by $[32,47]$ :

$$
g_{t h}=\frac{2 \pi n_{g}}{\lambda Q \Gamma}
$$

where $n_{g}$ is the group refractive index of the active region, $\lambda$ is the resonance wavelength, $Q$ is the quality factor and $\Gamma$ is the confinement factor. $\lambda$ and $Q$ are calculated from the eigenfrequencies of the eigenmodes. $\Gamma$ is the confinement factor which is calculated as the ratio of total electric energy density in the active region and in the whole core-shell MCSNL. From (1), it can be seen that the general rules for designing a SNL with a low threshold gain is to (i) to increase the $\mathrm{Q}$ factor which can be achieved by avoiding modal overlap with the metal and (ii) to maximize the mode confinement in the active region.

\section{B. Model for Electrical and Thermal Simulations}

The electrical and thermal simulations are performed together by coupling the Semiconductor interface in the Semiconductor module and the Heat Transfer in Solid interface in the Heat Transfer module. The Semiconductor interface solves Poisson's equation in conjunction with continuity equations for the charge carriers considering Fermi-Dirac statistics. The Heat Transfer in Solid interface solves the heat balance equation in time.

Using an initial temperature, the heat generated in the Semiconductor interface, including joule and non-radiative recombination heating, due to electrical injection are used as the heat source in the Heat Transfer in Solid interface which calculates the temperature distribution. This temperature distribution is then fed back to the Semiconductor interface which re-calculates the heat source and again provides the heat source to the Heat Transfer in Solid interface to update the temperature distribution. This process iterates several times until the steady-state of the temperature distribution is reached.

In the model, 2D axial-symmetric geometry is used where the ambient temperature is set to be $300 \mathrm{~K}$ and the bottom of the Sapphire is set to a constant temperature of $300 \mathrm{~K}$ to act as a heat sink. The Metal Contact boundary condition is used to inject the carries into the laser where the holes are injected from top surface of the P GaN ( $\mathrm{p}$ doped $1.0 \times 10^{19} \mathrm{~cm}^{-3}$ ) shell and electrons are injected from the $\mathrm{N} \mathrm{GaN}$ (n doped $1.0 \times 10^{19} \mathrm{~cm}^{-3}$ ) layer sit on top of the sapphire substrate. The maximum element size in the active region is set to be $5 \mathrm{~nm}$ which is gradually increased and swept over the whole geometry. Several key physical processes, including radiative recombination, Auger recombination, trap-assisted recombination and convective heat flux via the metal, are considered in the simulations. Parameters used for electrical and thermal simulations are listed in Table III and IV.

TABLE III

PARAMETERS USED IN THE ELECTRICAL SIMULATIONS

\begin{tabular}{c|c}
\hline \hline Material & $\mathrm{GaN}(\mathrm{InGaN})$ \\
\hline Parameters & $3.39 \mathrm{eV}(2.67 \mathrm{eV})[52]$ \\
Band gap & $4.1 \mathrm{~V}[53]$ \\
Electron affinity & $(\mathrm{T} / 1 \mathrm{~K})^{3 / 2} \times 8.9 \times 10^{15} \mathrm{~cm}^{-3 *}[54]$ \\
Effective density of states & \\
(Valence band) & $(\mathrm{T} / 1 \mathrm{~K})^{3 / 2} \times 4.3 \times 10^{14} \mathrm{~cm}^{-3 *}[54]$ \\
Effective density of states & $1000 \mathrm{~cm}^{2} \mathrm{~V}^{-1} \mathrm{~s}^{-1}[55]$ \\
(Conduction band) & $200 \mathrm{~cm}^{2} \mathrm{~V}^{-1} \mathrm{~s}^{-1}[56]$ \\
Electron mobility & $1.0 \times 10^{-11} \mathrm{~cm}^{3} \mathrm{~s}^{-1}[57]$ \\
Hole mobility & $6.15 \times 10^{-33} \mathrm{~cm}^{6} \mathrm{~s}^{-1}[42]$ \\
Radiative recombination factor & $2.0 \times 10^{-7} \mathrm{~s}[57]$ \\
Auger recombination factor & \\
SRH recombination factor &
\end{tabular}

${ }^{*} \mathrm{~T}$ is the temperature.

\section{OPTICAL SIMULATION RESULTS}

In this section, attention is given to a range of circumstances in which the core-shell MCSNLs are shown to have low losses where the carrier density is $6 \times 10^{19} \mathrm{~cm}^{-3}$ and temperature is 300 $\mathrm{K}$. This carrier density and temperature will be used as a reference for the electrical and thermal simulation results shown in the following sections. Figure 2 shows the influence of N GaN thickness on the threshold gain and $Q$ factor of the core-shell MCSNL where $r_{N}=200 \mathrm{~nm}, t_{M Q W}=96 \mathrm{~nm}, t_{P}=80 \mathrm{~nm}$ and $t_{S}=40 \mathrm{~nm}$. From Fig. 2, it can be seen that $g_{\text {th }}$ decreases with the increase of $t_{N}$ and $Q$ increases with the increase of $t_{N}$. Also, with the increase of $t_{N}$, the wavelength is red-shifted which makes the material gain, $g_{0}$, move towards its peak as shown in [44] where the wavelength is $465.60 \mathrm{~nm}$. 
TABLE IV

PARAMETERS USED IN THE THERMAL SIMULATIONS

\begin{tabular}{c|cccc}
\hline \hline Material & \multirow{2}{*}{$\mathrm{GaN}(\mathrm{InGaN})$} & $\mathrm{SiO} 2$ & $\mathrm{Ag}$ & Sapphire \\
Parameters & $130 \mathrm{Wm}^{-1} \mathrm{~K}^{-1}[58]$ & $1.4 \mathrm{Wm}^{-1} \mathrm{~K}^{-1}[59]$ & $429 \mathrm{Wm}^{-1} \mathrm{~K}^{-1}[60]$ & $35 \mathrm{Wm}^{-1} \mathrm{~K}^{-1}[61]$ \\
Thermal conductivity & $6070 \mathrm{kgm}^{-3}[62]$ & $2200 \mathrm{kgm}^{-3}[63]$ & $10500 \mathrm{kgm}^{-3}[64]$ & $3965 \mathrm{kgm}^{-3}[65]$ \\
Density & $490 \mathrm{Jkg}^{-1} \mathrm{~K}^{-1}[66]$ & $730 \mathrm{Jkg}^{-1} \mathrm{~K}^{-1}[67]$ & $235 \mathrm{Jkg}^{-1} \mathrm{~K}^{-1}[64]$ & $880 \mathrm{Jkg}^{-1} \mathrm{~K}^{-1}[65]$ \\
\hline Heat capacity at constant pressure
\end{tabular}

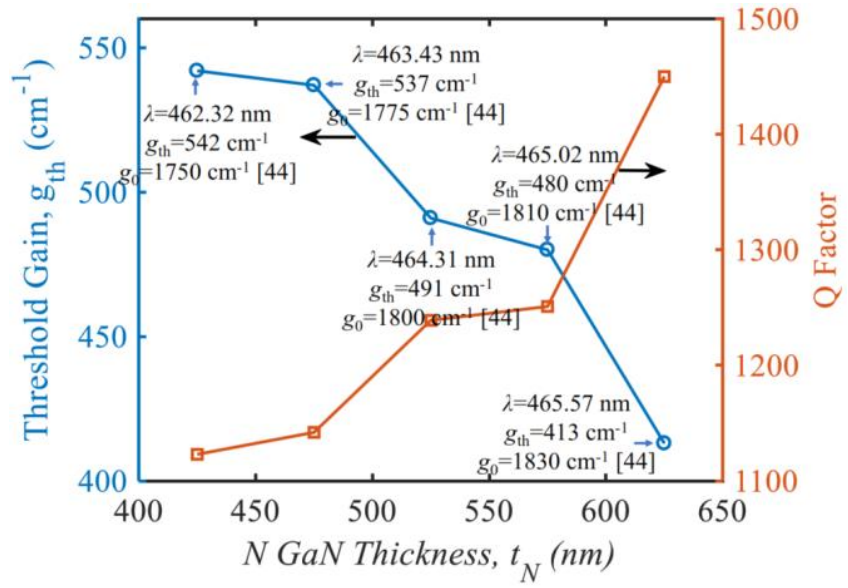

Fig. 2. The influence of $\mathrm{N} \mathrm{GaN}$ thickness on the threshold gain and $\mathrm{Q}$ factor of the core-shell MCSNL where $r_{N}=200 \mathrm{~nm}, t_{M Q W}=96 \mathrm{~nm}, t_{P}=80 \mathrm{~nm}$ and $t_{S}=40$ nm.

The modes are whispering-gallery modes $\left(\mathrm{WGM}_{\mathrm{m}, \mathrm{n}}\right)$ with the azimuthal mode number $(m)$ of 6 and radial mode number $(n)$ of 2. An example of the mode profile, in terms of electric field intensity, is shown in Fig. 3 when $t_{N}=625 \mathrm{~nm}$. The threshold gains shown in Fig. 2 are all lower than the material gain calculated in [44] and therefore lasing can be supported. In particular, when $t_{N}=625 \mathrm{~nm}, g_{\text {th }}$ is only $413 \mathrm{~cm}^{-1}$ which is much lower than the material gain $\left(g_{0}=1830 \mathrm{~cm}^{-1}\right)$ calculated in [44]. The corresponding mode is shown in Fig. 3. It can be seen that this WGM is well confined in the core-shell MCSNL due to the metal coating. Most of the first order radial mode, which occupies the majority of the electric field intensity, is well confined in the active region with $\Gamma=55.2 \%$. This $\Gamma$ will decrease, e.g., $\Gamma=54.2 \%$ when $t_{N}=475 \mathrm{~nm}$, with decrease of nanolaser height as parts of the mode leak into the substrate and the top P GaN where additional losses can also be introduced due to the metal coated on top of the P GaN. This is why $g_{\text {th }}$ increases with decrease of $t_{N}$ as shown in Fig. 2.

(a)

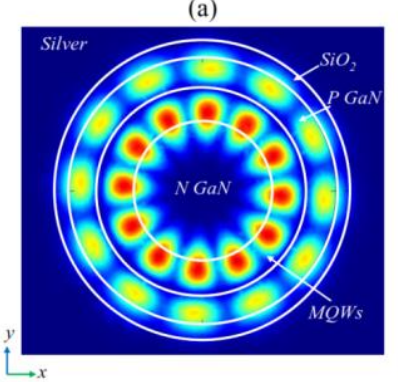

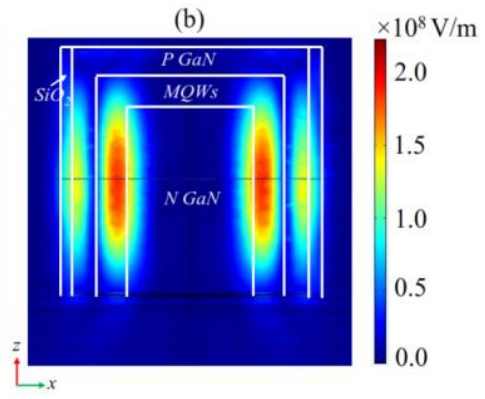

Fig. 3. The electric field amplitude intensity $\left(\mathrm{WGM}_{6,2}\right)$ in a core-shell MCSNL where $r_{N}=200 \mathrm{~nm}, t_{N}=625 \mathrm{~nm}, t_{M Q W}=96 \mathrm{~nm}, t_{P}=80 \mathrm{~nm}$ and $t_{S}=40 \mathrm{~nm}$. (a) horizontal cross section, (b) vertical cross section.

Attention is now given to the effect of the $\mathrm{SiO}_{2}$ thickness on the threshold gain and the $Q$ factor of the core-shell MCSNL where $r_{N}=200 \mathrm{~nm}, t_{N}=625 \mathrm{~nm}, t_{M Q W}=96 \mathrm{~nm}$ and $t_{P}=80 \mathrm{~nm}$. Figure 4 shows the effect of $\mathrm{SiO}_{2}$ thickness where the threshold gain decreases with increase of $t_{S}$ and the $Q$ factor increases with the increase of $t_{S}$. This is because increase of the $\mathrm{SiO}_{2}$ thickness increases the distance between the mode and metal thus reducing the losses. However, when the $\mathrm{SiO}_{2}$ thickness is larger than $40 \mathrm{~nm}$, the $g_{0}$ starts to decrease dramatically from $1830 \mathrm{~cm}^{-1}\left(t_{S}=40 \mathrm{~nm}\right)$ to $190 \mathrm{~cm}^{-1}\left(t_{S}=60 \mathrm{~nm}\right)$ where the wavelength red-shifts from $465.57 \mathrm{~nm}$ to $473.13 \mathrm{~nm}$ according to the gain spectrum in [44]. Such a rapid drop of material gain means that the device will not lase as it cannot overcome the losses, e.g., $g_{0}<g_{\text {th }}$ when $t_{S}=60 \mathrm{~nm}$ as shown in Fig. 4. Therefore, careful choice of $\mathrm{SiO}_{2}$ thickness should be made for the core-shell MCSNLs. The modes are still $\mathrm{WGM}_{6,2}$ which are similar to the one shown in Fig. 3.

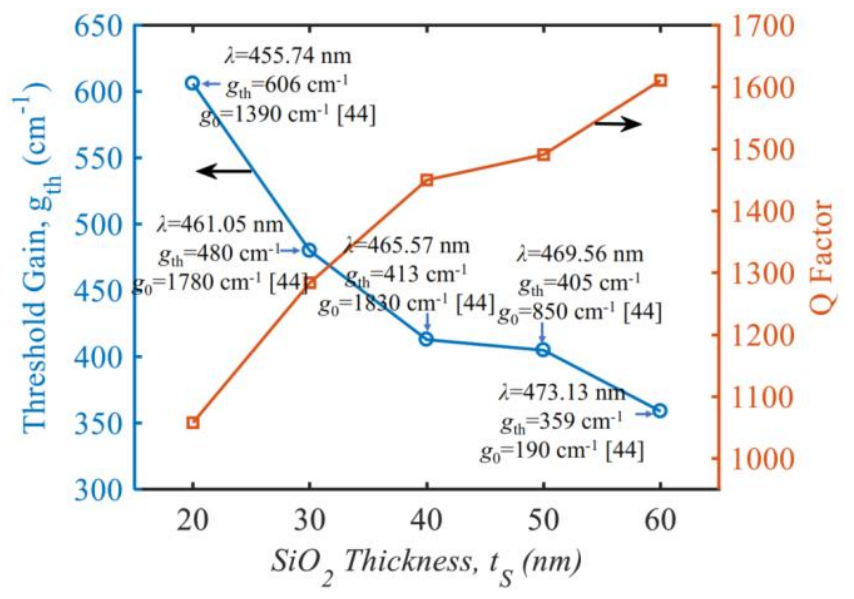

Fig. 4. The influence of $\mathrm{SiO}_{2}$ thickness on the threshold gain and $Q$ factor of the core-shell MCSNL where $r_{N}=200 \mathrm{~nm}, t_{N}=625 \mathrm{~nm}, t_{M Q W}=96 \mathrm{~nm}$ and $t_{P}=80 \mathrm{~nm}$.

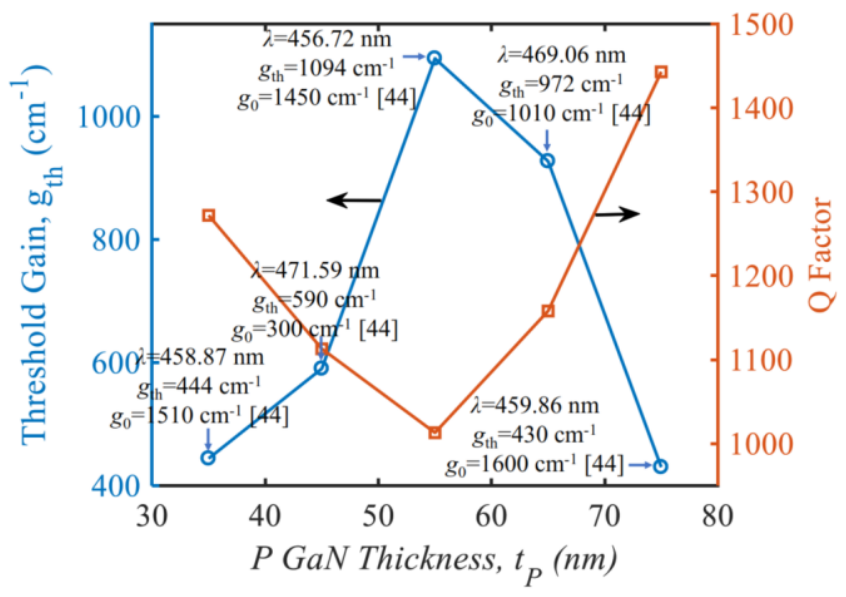

Fig. 5. The influence of $\mathrm{P}$ GaN thickness on the threshold gain and $Q$ factor of the core-shell MCSNL where $r_{N}=200 \mathrm{~nm}, t_{N}=625 \mathrm{~nm}, t_{M Q W}=96 \mathrm{~nm}$ and $t_{S}=40$ $\mathrm{nm}$. 


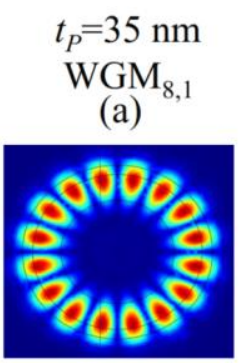

(f)

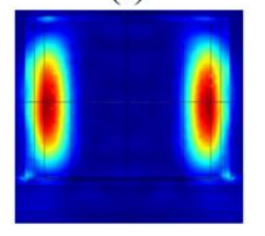

$t_{P}=45 \mathrm{~nm}$

$\mathrm{WGM}_{8,1}$

(b)

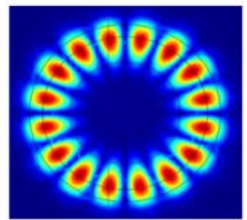

(g)

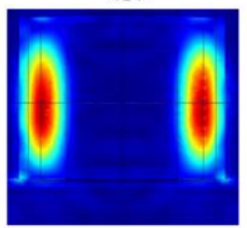

$t_{P}=55 \mathrm{~nm}$

WGM $_{3,3}$

(c)

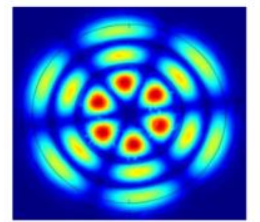

(h)

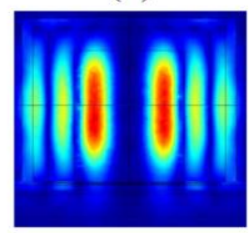

$t_{P}=65 \mathrm{~nm}$

$\mathrm{WGM}_{3,3}$

(d)

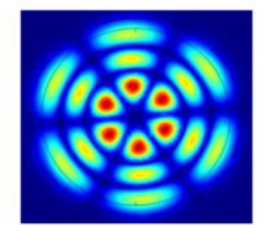

(i)

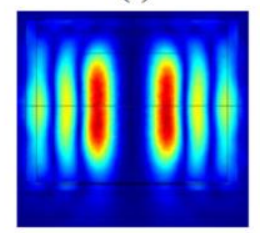

$t_{P}=75 \mathrm{~nm}$

WGM $_{6,2}$

(e)

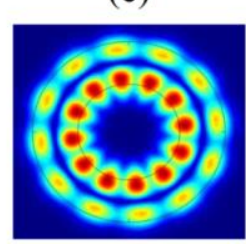

(j)

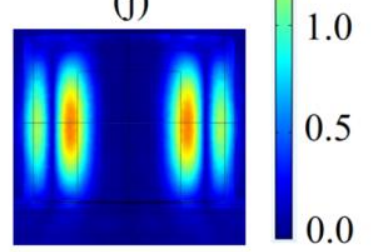

$\times 10^{8} \mathrm{~V} / \mathrm{m}$

2.0

1.5

0

5
Attention is finally given to the effect of the $\mathrm{P} G a N$ thickness on the threshold gain and the $Q$ factor of the core-shell MCSNL where $r_{N}=200 \mathrm{~nm}, t_{N}=650 \mathrm{~nm}, t_{M Q W}=96 \mathrm{~nm}$ and $t_{S}=40 \mathrm{~nm}$. With increase of $t_{P}$ thickness, the threshold gain firstly increases to a maximum of $1094 \mathrm{~cm}^{-1}$ when $t_{P}=55 \mathrm{~nm}$ and then decreases to its minimum of $430 \mathrm{~cm}^{-1}$ when $t_{P}=75 \mathrm{~nm}$ as shown in Fig. 5 where the $Q$ factor shows a opposite trend to the threshold gain. The wavelength varies irregularly and thus also does the gain. The biggest difference of gain-loss is $1170 \mathrm{~cm}^{-1}$ when $t_{P}=75 \mathrm{~nm}$.

The corresponding profiles of the modes in Fig. 5 are shown in Fig. 6. From Fig. 6, it can be seen that the mode profile varies with change of $\mathrm{P} \mathrm{GaN}$ thickness. When $t_{P}=35$ and $45 \mathrm{~nm}$, the modes are $\mathrm{WGM}_{8,1}$ and the $t_{P}=35 \mathrm{~nm}$ has more mode confinement in the MQWs than $t_{P}=45 \mathrm{~nm}$, and thus a lower threshold gain. However, when $t_{P}=55$ and $65 \mathrm{~nm}$, the modes changes to $\mathrm{WGM}_{3,3}$ and most of their electric field intensities are located in the $\mathrm{N} \mathrm{GaN}$ rather than in the MQWs which leads to a significant increase of the threshold gain. When $t_{p}=75 \mathrm{~nm}$, the mode changes to $\mathrm{WGM}_{6,2}$ where most of the electric field intensity of the mode returns to the MQWs. The above effect of P GaN thickness on the modes' behavior is caused by the mode coupling between the co-existing WGM in the cavity with different angular and radial mode numbers. Detailed analysis of mode coupling in the core shell nano-resonator can be found in [68].

\section{ELECTRICAL AND THERMAL SIMULATION RESULTS}

The threshold carrier density can be obtained from the steady state form of the laser rate equations. In this situation, the threshold carrier density $N_{\text {th }}=N_{0}+1 /\left(G_{\mathrm{N}} \tau_{\mathrm{P}}\right)$ where $N_{0}=9.3 \times 10^{19}$ $\mathrm{cm}^{-3}$ [69] is the carrier density at transparency, $G_{\mathrm{N}}$ is the gain coefficient and $\tau_{\mathrm{P}}$ is the photon life time. $G_{\mathrm{N}}=v_{\mathrm{g}} g$ where $v_{\mathrm{g}}$ is the group velocity and $g=5.8 \times 10^{-17} \mathrm{~cm}^{2}[69]$ is the differential gain. $\tau_{\mathrm{P}}=Q \lambda /(2 \pi c)$ where $Q$ and $\lambda$ are extracted from the optical simulation results. $c$ is the speed of light. For the core-shell MCSNL shown in Fig. 3 which has the optimal structure with the lowest threshold gain, the calculated threshold carrier density is $N_{\mathrm{th}}=9.7 \times 10^{19} \mathrm{~cm}^{-3}$. The electrical simulation then shows that the corresponding voltage across and injection current through the core-shell MCSNL are respectively $3.45 \mathrm{~V}$ and $1.5 \mathrm{~mA}\left(I_{\mathrm{th}}\right)$.

Figure 7(a) shows the temperature distribution and heat flux (shown as the red arrows) at threshold. From Fig. 7(a), it can be seen that the majority of the heat generated, largely attributed to the increase of Joule heating, is located around the bottom of $\mathrm{P}$ $\mathrm{GaN}$ which dissipates through the top coated metal and the substrate. The maximum temperature is $303 \mathrm{~K}$ which is only 3 $\mathrm{K}$ above the ambient temperature. Generally, increase of temperature will decrease the material gain (which is calculated when temperature is $300 \mathrm{~K}$ and the carrier density is $6 \times 10^{19}$ $\mathrm{cm}^{-3}$ ). However, the carrier density in this case is $9.7 \times 10^{19} \mathrm{~cm}^{-3}$ where the maximum material gain is expected to be above 2500 $\mathrm{cm}^{-1}$ when the temperature is $300 \mathrm{~K}$ (see Fig. 12 in [44]). Therefore, it is expected the reduction of $g_{0}$ due to a $3 \mathrm{~K}$ increase of temperature can be sufficiently compensated by increasing the carrier density. In this situation, the material gain is more than six times larger than the loss without significant increase of temperature, thus further confirming the possibility of lasing in the core-shell MCSNL. (a)

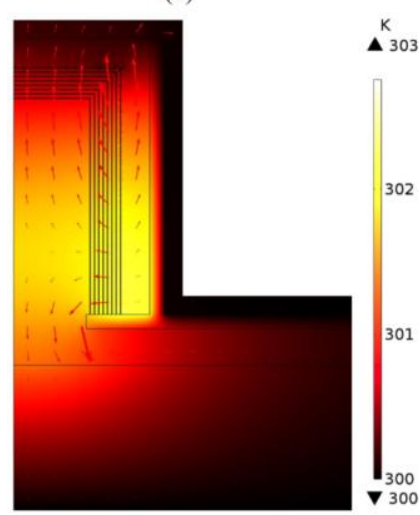

(b)

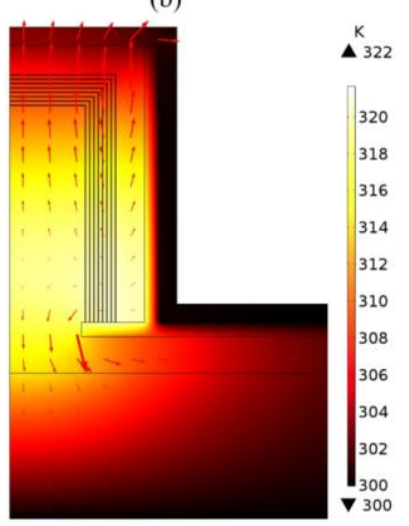

Fig. 7. The temperature distribution and heat flux (red arrows) in the core-shell MCSNL. (a) when the carrier density reaches $N_{\mathrm{th}}=9.7 \times 10^{19} \mathrm{~cm}^{-3}$ where voltage $=3.45 \mathrm{~V}$, current $=1.5 \mathrm{~mA}$, (b) voltage $=4.00 \mathrm{~V}$, current $=7.6 \mathrm{~mA}$.

With a further increase of injection current to $5.1 I_{\text {th }}$ (the voltage is $4.00 \mathrm{~V}$ ), the maximum temperature reaches $322 \mathrm{~K}$ and the heat also dissipates through the top coated metal and the 
substrate as shown in Fig. 7(b). Such an increased temperature is still in an acceptable range where the gain is not expected to decrease significantly. The good thermal management of the core-shell MCSNL may be attributed to the large thermal conductivities of GaN and large heat capacity of the sapphire substrate. For example, for the MCSNL lasing in the near infrared region which suffers from self-heating problem [32], the thermal conductivity of the active region (InGaAs) is only $16 \mathrm{Wm}^{-1} \mathrm{~K}^{-1}$ [32] which is much less than $\mathrm{GaN}\left(130 \mathrm{Wm}^{-1} \mathrm{~K}^{-1}\right.$ as shown in Table IV). Also, the heat capacity of the InP substrate (310 $\left.\mathrm{Jkg}^{-1} \mathrm{~K}^{-1}[70]\right)$ is less than that of the sapphire substrate $\left(880 \mathrm{Jkg}^{-1} \mathrm{~K}^{-1}\right.$ as shown in Table IV).

\section{CONCLUSION}

In paper, we have designed a metal coated semiconductor nanolaser (SNL) with an $\mathrm{GaN} /(\mathrm{InGaN} / \mathrm{GaN} \mathrm{MQWs}) / \mathrm{GaN}$ core-shell structure. Numerical results demonstrate that the threshold gain of the SNL is more than four times lower than the material gain calculated in [44] due to the large mode confinement in the active region. Such a low threshold gain indicates the possibility of achieving room temperature (RT) continuous wave (CW) operation of the SNL under electrical injection. This is confirmed by our further simulations which show there is no significant over-heating problem when the SNL is operated well above threshold. The designs of SNL presented in this paper are considered to be helpful for the realization of an electrically pumped RT CW SNL operating in the visible spectral region.

\section{REFERENCES}

[1] C. Z. Ning., "Semiconductor nanolasers," Physica Status Solidi (b), vol. 247, no. 4, pp. 774-788, Mar. 2010.

[2] D. Saxena, S. Mokkapati, and C. Jagadish, "Semiconductor nanolasers," IEEE J. Photon., vol. 4, no. 2, pp. 582-585, Apr. 2012.

[3] Q. Gu and Y. Fainman, Semiconductor Nanolasers. Cambridge: Cambridge University Press, 2017.

[4] M. Khajavikhan et al., "Thresholdless nanoscale coaxial lasers," Nature, vol. 482, pp. 204-207, Feb. 2012.

[5] W. Wei, X. Yan, and X. Zhang, "Ultrahigh Purcell factor in low-threshold nanolaser based on asymmetric hybrid plasmonic cavity," Scientific Reports, vol. 6, article no. 33063, Sep. 2016.

[6] Y. Ota, M. Kakuda, K. Watanabe, S. Iwamoto, and Y. Arakawa, "Thresholdless quantum dot nanolaser," Opt. Express, vol. 25, no. 17, pp. 19981-19994, Aug. 2017.

[7] K. A. Shore, "Modulation bandwidth of metal-clad semiconductor nanolasers with cavity-enhanced spontaneous emission," Electron. Lett., vol. 46 , no. 25 , pp. 1688 - 1689, Dec. 2010

[8] T. Suhr, N. Gregersen, K. Yvind, and J. Mørk, "Modulation response of nanoLEDs and nanolasers exploiting Purcell enhanced spontaneous emission," Opt. Express, vol. 18, no. 11, pp. 11230-11241, May 2010.

[9] N. Li, K. Liu, V. J. Sorger, and D. K. Sadana, "Monolithic III-V on silicon plasmonic nanolaser structure for optical interconnects," Scientific Reports, vol. 5, article no. 14067, Sep. 2015.

[10] R. Chen et al., "Nanolasers grown on silicon," Nat. Photon., vol. 5, pp. 170-175, Feb. 2011.

[11] G. Crosnier et al., "Hybrid indium phosphide-on-silicon nanolaser diode," Nat. Photon., vol. 11, pp. 297-300, Apr. 2017.

[12] A. Hazari et al., "1.3um optical interconnect on silicon: A monolithic III-Nitride nanowire photonic integrated circuit," IEEE J. Quantum Electron., vol. 53, no. 4, article no. 6300109, Aug. 2017.

[13] X. Duan, Y. Huang, R. Agarwal, and C. M. Lieber, "Single-nanowire electrically driven lasers," Nature, vol. 421, pp. 241-245, Jan. 2003.

[14] H. G. Park et al., "Electrically driven single-cell photonic crystal laser," Science, vol. 305, no. 5689, pp. 1444-1447, Sep. 2004.

[15] M. T. Hill et al., "Lasing in metallic-coated nanocavities," Nat. Photon., vol. 1, pp. 589-594, Sep. 2007.
[16] C. Manolatou and F. Rana, "Subwavelength nanopatch cavities for semiconductor plasmon lasers," IEEE J. Quantum Electron., vol. 44, no. 5, pp. 435-447, May 2008.

[17] M. T. Hill et al., "Lasing in metal-insulator-metal sub-wavelength plasmonic waveguides," Opt. Express, vol. 17, no. 13, pp. 11107-11112, Jun. 2009.

[18] R. Yan, D. Gargas, and P. Yang, "Nanowire photonics," Nat. Photon., vol. 3, pp. 569-576, Oct. 2009.

[19] M. P. Nezhad et al., "Room-temperature subwavelength metallo-dielectric lasers," Nat. Photon., vol. 4, pp. 395-399, Apr. 2010.

[20] K. Yu, A. Lakhani, and M. C. Wu, "Subwavelength metal-optic semiconductor nanopatch lasers," Opt. Express, vol. 18, no. 9, pp. 8790-8799, Apr. 2010.

[21] M. L. Amit, Y. Kyoungsik, and C. W. Ming, "Lasing in subwavelength semiconductor nanopatches," Semicond. Sci. Technol., vol. 26, no. 1, article no. 014013, Nov. 2011.

[22] Q. Ding, A. Mizrahi, Y. Fainman, and V. Lomakin, "Dielectric shielded nanoscale patch laser resonators," Opt. Lett., vol. 36, no. 10, pp. 1812-1814, May 2011.

[23] J. H. Lee et al., "Electrically pumped sub-wavelength metallo-dielectric pedestal pillar lasers," Opt. Express, vol. 19, no. 22, pp. 21524-21531, Oct. 2011.

[24] Y. J. Lu et al., "Plasmonic nanolaser using epitaxially grown silver film," Science, vol. 337, no. 6093, pp. 450-453, Jul. 2012.

[25] K. Ding et al., "Room-temperature continuous wave lasing in deep-subwavelength metallic cavities under electrical injection," Phys. Rev. $B$, vol. 85, no. 4, article no. 041301, Jan. 2012.

[26] K. Ding, M. T. Hill, Z. C. Liu, L. J. Yin, P. J. van Veldhoven, and C. Z. Ning, "Record performance of electrical injection sub-wavelength metallic-cavity semiconductor lasers at room temperature," Opt. Express, vol. 21, no. 4, pp. 4728-4733, Feb. 2013.

[27] Y. Hou, P. Renwick, B. Liu, J. Bai, and T. Wang, "Room temperature plasmonic lasing in a continuous wave operation mode from an $\mathrm{InGaN} / \mathrm{GaN}$ single nanorod with a low threshold," Scientific Reports, vol. 4, article no. 5014, May 2014.

[28] K. H. Li, X. Liu, Q. Wang, S. Zhao, and Z. Mi, "Ultralow-threshold electrically injected AlGaN nanowire ultraviolet lasers on $\mathrm{Si}$ operating at low temperature," Nat. Nanotechnol., vol. 10, pp. 140-144, Jan. 2015.

[29] C. Li et al., "Nonpolar InGaN/GaN core-shell single nanowire lasers," Nano Lett., vol. 17, no. 2, pp. 1049-1055, Jan. 2017.

[30] C. Y. Huang et al., "Collective lasing behavior of monolithic GaN-InGaN core-shell nanorod lattice under room temperature," Nano Lett., vol. 17, no. 10, pp. 6228-6234, Sep. 2017.

[31] K. Ding and C. Z. Ning, "Metallic subwavelength-cavity semiconductor nanolasers," Light: Science \& Applications, vol. 1, article no. e20, Jul. 2012.

[32] Q. Gu et al., "Amorphous $\mathrm{Al}_{2} \mathrm{O}_{3}$ shield for thermal management in electrically pumped metallo-dielectric nanolasers," IEEE J. Quantum Electron., vol. 50, no. 7, pp. 499-509, Jul. 2014.

[33] J. Shane, Q. Gu, A. Potterton, and Y. Fainman, "Effect of undercut etch on performance and fabrication robustness of metal-clad semiconductor nanolasers," IEEE J. Quantum Electron., vol. 51, no. 1, article no. 2000109, Jan. 2015.

[34] A. Mizrahi, V. Lomakin, B. A. Slutsky, M. P. Nezhad, L. Feng, and Y. Fainman, "Low threshold gain metal coated laser nanoresonators," Opt. Lett., vol. 33, no. 11, pp. 1261-1263, Jun. 2008.

[35] Y.-H. Chou et al., "Ultrastrong mode confinement in $\mathrm{ZnO}$ surface plasmon nanolasers," ACS Nano, vol. 9, no. 4, pp. 3978-3983, Apr. 2015.

[36] Y.-H. Chou et al., "High-operation-temperature plasmonic nanolasers on single-crystalline aluminum," Nano Lett, vol. 16, no. 5, pp. 3179-3186, May 2016.

[37] Y.-H. Chou et al., "Ultracompact pseudowedge plasmonic lasers and laser arrays," Nano Lett., vol. 18, no. 2, pp. 747-753, Feb. 2018.

[38] M. Athanasiou, R. Smith, B. Liu, and T. Wang, "Room temperature continuous-wave green lasing from an InGaN microdisk on silicon," Scientific Reports, vol. 4, article no. 7250, Nov. 2014.

[39] Z. Liu, K. Wang, X. Luo, and S. Liu, "Precise optical modeling of blue light-emitting diodes by Monte Carlo ray-tracing," Opt. Express, vol. 18, no. 9, pp. 9398-9412, Apr. 2010.

[40] D. F. Feezell, J. S. Speck, S. P. DenBaars, and S. Nakamura, "Semipolar (2021) InGaN/GaN light-emitting diodes for high-efficiency solid-state lighting," J. Disp. Technol., vol. 9, no. 4, pp. 190-198, Apr. 2013.

[41] T. Melo et al., "Gain comparison in polar and nonpolar/semipolar gallium-nitride-based laser diodes," Semicond. Sci. Technol., vol. 27, no. 2, article no. 024015, Jan. 2012. 
[42] S. Boubanga-Tombet et al., "Ultrafast carrier capture and auger recombination in single $\mathrm{GaN} / \mathrm{InGaN}$ multiple quantum well nanowires," ACS Photon., vol. 3, no. 12, pp. 2237-2242, Nov. 2016.

[43] P. Zhang, Q. Gu, Y. Y. Lau, and Y. Fainman, "Constriction resistance and current crowding in electrically pumped semiconductor nanolasers with the presence of undercut and sidewall tilt," IEEE J. Quantum Electron., vol. 52, no. 3, article no. 2000207, Jan. 2016.

[44] H. Zhao, R. A. Arif, Y. K. Ee, and N. Tansu, "Self-consistent analysis of strain-compensated InGaN-AlGaN quantum wells for lasers and light-emitting diodes," IEEE J. Quantum Electron., vol. 45, no. 1, pp. 66-78, Jan. 2009

[45] J. N. Reddy, Introduction to the Finite Element Method, Third Edition, McGraw-Hill Education, 2006

[46] "Axisymmetric cavity resonator." [Online]. Available: https://www.comsol.com/model/download/479461/models.rf.axisymmetric cavity_resonator.pdf

[47] S. W. Chang and S. L. Chuang, "Fundamental formulation for plasmonic nanolasers," IEEE J. Quantum Electron., vol. 45, no. 8, pp. 1014-1023, Aug. 2009.

[48] T. Radhakrishnan, "Further studies on the temperature variation of the refractive index of crystals," Proc. of the Indian Academy of Sciences Section A, vol. 33, no. 22, pp. 22-34, Jan. 1951

[49] I. H. Malitson, "Refraction and dispersion of synthetic sapphire," J. Opt. Soci. of Ameri., vol. 52, no.12, pp. 1377-1379, Dec. 1962.

[50] P. B. Johnson and R. W. Christy, "Optical constants of the noble metals," Phys. Rev. B, vol. 6, no. 12, pp. 4370-4379, Dec. 1972.

[51] P. E. Ciddor, "Refractive index of air: new equations for the visible and near infrared," Appl. Opt., vol. 35, no. 9, pp. 1566-1573, Mar. 1996.

[52] P. G. Moses and C. G. Van de Walle, "Band bowing and band alignment in InGaN alloys," Appl. Phys. Lett., vol. 96, article no. 021908, Jan. 2010.

[53] M. E. Levinshtein, S. L. Rumyantsev and M. S. Shur, Properties of Advanced Semiconductor Materials GaN, AlN, InN, BN, SiC, SiGe. New York: John Wiley \& Sons, 2001.

[54] V. K. Khanna, Fundamentals of Solid-State Lighting: LEDs, OLEDs, and Their Applications in Illumination and Displays. CRC Press, 2014

[55] W. Götz, N. M. Johnson, C. Chen, H. Liu, C. Kuo, and W. Imler, "Activation energies of Si donors in GaN," Appl. Phys. Lett., vol. 68, no. 22, pp. 3144-3146, May 1996.

[56] J. H. Edgar, Properties of Group III Nitrides. London: The Institution of Engineering \& Technology, 1994.

[57] G. Kim, J. H. Kim, E. H. Park, D. Kang, and B. G. Park, "Extraction of recombination coefficients and internal quantum efficiency of GaN-based light emitting diodes considering effective volume of active region," Opt. Express, vol. 22, no. 2, pp. 1235-1242, Jan. 2014.

[58] C. Mion, "Investigation of the thermal properties of gallium nitride using the three omega technique," Ph.D. dissertation, North Carolina State University, Raleigh, NC, USA, 2006.

[59] M. B. Kleiner, S. A. Kuhn, and W. Weber, "Thermal conductivity measurements of thin silicon dioxide films in integrated circuits," IEEE Trans. on Electron Dev., vol. 43, no. 9, pp. 1602-1609, Sep. 1996.

[60] N. A. Lange, Lange's Handbook of Chemistry, Sixteenth Edition, McGraw-Hill Professional, 2005.

[61] B. Gao and K. Kakimoto, "Modeling grown-in dislocation multiplication on prismatic slip planes for GaN single crystals," J. Appl. Phys., vol. 117, article no. 035701, Jan. 2015.

[62] W. M. Haynes, CRC Handbook of Chemistry and Physics, 95 ${ }^{\text {th }}$ Edition, CRC Press, 2014

[63] E. Bassous, "Fabrication of novel three-dimensional microstructures by the anisotropic etching of (100) and (110) silicon," IEEE Trans. on Electron Dev., vol. 25, no. 10, pp. 1178-1185, Oct. 1978.

[64] D. R. Lide, CRC Handbook of Chemistry and Physics, 84 ${ }^{\text {th }}$ Edition, CRC Press, 2003

[65] H. H. E. Dörre, Alumina: processing, properties, and applications. Berlin: Springer-Verlag, 1984

[66] X. L. Chen et al., "Structure and heat capacity of wurtzite GaN from 113 to 1073 K," Chinese Phys. Lett., vol. 16, no. 2, pp. 107-108, 1999.

[67] S. Andersson and L. Dzhavadov, "Thermal conductivity and heat capacity of amorphous $\mathrm{SiO}_{2}$ : pressure and volume dependence," J. Phys.: Condens. Matter, vol. 4, no. 29, p. 6209-6216, Mar. 1992.

[68] Q. F. Yao, Y. Z. Huang, L. X. Zou, X. M. Lv, J. D. Lin, and Y. D. Yang, "Analysis of mode coupling and threshold gain control for nanocircular resonators confined by isolation and metallic layers," J. Lightw. Technol., vol. 31, no. 3, pp. 786-792, Mar. 2013.

[69] S. Nakamura, "InGaN-based blue laser diodes," IEEE J. Sel. Topics Quantum Electron., vol. 3, no. 3, pp. 712-718, Jun. 1997.
[70] M. E. Levinshtein, S. L. Rumyantsev and M. S. Shur, Handbook series on semiconductor parameters, Volume 1: Si, Ge, C (diamond), GaAs, GaP, GaSb, InAs, InP, InSb. London: World Scientific, 1996.

Yuanlong Fan received the B.E. degree from Dalian University of Technology, China, in 2009 and his M.E. and Ph.D. degrees from the University of Wollongong, Australia, in 2011 and 2016. He was a recipient of the Australian Endeavour Fellowship to undertake postdoctoral research at the University of Wollongong, Australia in 2016.

He is currently a research officer at the School of Electronic Engineering, Bangor University, United Kingdom. His research interests include design of semiconductor nanolasers, nonlinear dynamics of semiconductor (nano)lasers, fiber nonlinear optics, and optical signal processing.

K. Alan Shore (SM'95) received the degree in mathematics from the University of Oxford, Oxford, U.K., and the Ph.D. degree from University College, Cardiff, Wales, U.K

He was a Lecturer with the University of Liverpool from 1979 to 1983 and with the University of Bath, where he became a Senior Lecturer in 1986, a Reader in 1990, and a Professor in 1995. He was a Visiting Researcher with the Center for High Technology Materials, University of New Mexico, Albuquerque, USA, in 1987. In 1989, he was a Visiting Researcher with the Huygens Laboratory, Leiden University, The Netherlands. From 1990 to 1991, he was with the Teledanmark Research Laboratory and the MIDIT Center of the Technical University of Denmark, Lyngby. He was a Guest Researcher with the Electrotechnical Laboratory, Tsukuba, Japan, in 1991. In 1992, he was a Visiting Professor with the Department of Physics, University de les IllesBalears, Palma-Majorca, Spain. He was a Visiting Lecturer with the Instituto de Fisica de Cantabria, Santander, Spain, from 1996 to 1998, and a Visiting Researcher with the Department of Physics, Macquarie University, Sydney, Australia, in 1996, 1998, 2000, 2002, 2005, and 2008. In 2001, he was a Visiting Researcher with the ATR Adaptive Communications Laboratories, Kyoto, Japan. From 2001 to 2008, he was the Director of Industrial and Commercial Optoelectronics, a Welsh Development Agency Center of Excellence. Since 1995, he has been the Head of the School of Informatics, College of Physical and Applied Sciences, Bangor University. He has authored or co-authored more than 1000 contributions to archival journals, books, and technical conferences. With Prof. D. Kane, he co-edited the research monograph Unlocking Dynamical Diversity. His research work has been principally in the area of semiconductor optoelectronic device design and experimental characterization with particular emphasis on nonlinearities in laser diodes and semiconductor optical waveguides. His current research interests include nonlinear optics and its applications, and the design of nano-spin semiconductor lasers. In 1995, he was appointed as the Chair of Electronic Engineering with Bangor University. He was the Chair of the Welsh Optoelectronics Forum from 2006 to 2008 and has chaired the Photonics Academy for Wales, since its establishment in 2005. From 2008 to 2011, he was the Chair of the Quantum Electronics Commission of the International Union of Pure and Applied Physics.

Dr. Shore has been a Program Member for several OSA conferences. In 2010, he held a Japan Society for the Promotion of Science Invitation Fellowship with the Ultrafast Photonics Group, Graduate School of Materials Science, Nara Institute of Science and Technology, Nara, Japan. He is a Fellow of the Optical Society of America, the Institute of Physics, and the Learned Society of Wales for which he has served as a Council Member from 2012 to 2015 and from 2016 to 2019 and as its General Secretary from 2017-2020. He was a Co-Organizer of a Rank Prize Symposium on Nonlinear Dynamics in Lasers held at the Lake District, U.K., in 2002. He cofounded and from 1987 to 2012 acted as the Organizer and Program Committee Chair for the International Conference on Semiconductor and Integrated Optoelectronics, which is held annually in Cardiff, Wales, U.K. He chaired the Education and Training in Optics and Photonics conference held at the Technium OpTIC, Wales, 2009. He coordinated International Year of Light activities in Wales during 2015. He chaired the Science and Technology Committee of the National Eisteddfod of Wales in 2017. 